\title{
EDITORIAL
}

\section{Supporting TB clinicians managing difficult cases: the ERS/WHO Consilium}

\author{
Francesco Blasi*, Masoud Dara ${ }^{\#}$, Marieke J. van der Werf ${ }^{\mp}$ and Giovanni Battista Migliori ${ }^{+}$
}

$\mathbf{M}$ ultidrug-resistant tuberculosis (MDR-TB), defined as active TB cases infected by Mycobacterium tuberculosis strains that are resistant to isoniazid and rifampicin (the two most important anti-TB drugs currently in use), and extensively drug resistant tuberculosis (XDR-TB), defined as active $\mathrm{TB}$ cases caused by infection with strains that are resistant to at least one fluoroquinolone and one injectable second-line anti-TB drug in addition to resistance to isoniazid and rifampicin, attract interest at different levels [1-5]. In recent years the alarming rates of MDR- or XDR-TB in Eastern Europe and some other parts of the world, have resulted in strong expressions of concern from national and international partners, health authorities, and professional societies.

At the media level, the key words MDR-TB and XDR-TB attract spikes of citations and consistent interest, as a simple Google search can testify (fig. 1).

From the public health point of view, MDR- and XDR-TB is considered a serious threat for TB control and elimination. Therefore, the international community and national governments prioritise monitoring and evaluating prevalence rates and trends of drug resistant $\mathrm{TB}$ at both the global and the regional level $[2,3]$.

Recent evidence suggests that of the estimated 310,000 MDRTB cases among notified TB patients with pulmonary $\mathrm{TB}$ in 2011, 60\% occurred in India, China and the Russian Federation. XDR-TB is, at present, notified in 84 countries, although representative data on these difficult-to-treat cases are only available in 13 of them $[2,3]$.

The proportion of MDR-TB cases harbouring XDR-TB strains of M. tuberculosis was highest in Azerbaijan, Belarus, Estonia, Latvia, Lithuania and Tajikistan.

The prevalence of MDR-TB is dramatically high in several countries of the former Soviet Union, where 9-32\% of new TB cases and $\geqslant 50 \%$ of previously treated cases harbour MDR-TB strains $[2,3]$ (table 1$)$. In response to these alarming rates, the

\footnotetext{
*Dipartimento Fisiopatologia Medico-Chirurgica e dei Trapianti, University of Milan, IRCCS Fondazione Cà Granda, Milan, and +World Health Organization Collaborating Centre for Tuberculosis and Lung Diseases, Fondazione S. Maugeri, Care and Research Institute, Tradate, Italy. ${ }^{*}$ World Health Organization, Regional Office for Europe, Copenhagen, Denmark. "European Centre for Disease Prevention and Control, Stockholm, Sweden.

CORRESPONDENCE: G.B. Migliori, World Health Organization Collaborating Centre for Tuberculosis and Lung Diseases, Fondazione S. Maugeri, Care and Research Institute, Via Roncaccio 16, 21049, Tradate, Italy. E-mail: giovannibattista.migliori@fsm.it
}

53 member states of the World Health Organization (WHO) European Region have endorsed a five-year consolidated action plan to prevent and combat MDR- and XDR-TB in 2011-2015 [6].

In spite of the notable progress in case detection (the number of cases reported by the 27 high MDR-TB burden countries almost doubled between 2009 and 2011) we still rely on estimates: $3.7 \%$ of new cases and $20 \%$ of previously treated cases are estimated to have MDR-TB at the global level $[2,3]$.

As of today, the world record in terms of prevalence of MDRTB was observed in Minsk, Belarus, where it was identified in $35.3 \%$ of new cases and in $76.5 \%$ of those previously treated: this means that about half of the cases diagnosed in that setting harbour MDR-TB strains. This finding was also confirmed at the national level.

The clinical outcome of MDR- and XDR-TB cases is largely unsatisfactory [7-10] (table 2). In the largest ever published cohort of 9,153 MDR-TB cases from 32 observational cohorts supporting an individual data meta-analysis, the outcomes of these cases were unacceptably poor (success $54 \%$; default $23 \%$; failure/relapse $8 \%$; death 15\%) [11]. In XDR-TB cases and in those harbouring $M$. tuberculosis strains with resistance patterns beyond XDR, the outcomes were even worse, with success ranging from $40 \%$ to $19 \%$, failure/relapse from $15 \%$ to $54 \%$ and death from $15 \%$ to $35 \%$, respectively $[12,13]$.

Due to the frequent occurrence of adverse events, limited availability of second-line anti-TB drugs, the eminent risk of acquiring further resistance, associated conditions such as alcohol and drug abuse and problems in patients' adherence, physicians often face major challenges to successfully treat their patients.

The WHO recommends that management of MDR-TB cases is supervised by a specialised team, including complementary medical professionals able to cover several perspectives (clinical, both for adults and children; surgical; radiological; public health; psychological; and nursing, among others). Implementation of such a body (known as a consilium in some countries belonging to the former Soviet Union) is a requisite to apply for international TB control funding and concessionary pricing of medicines to treat MDR- and XDR-TB cases.

The Green Light Committee for Europe, a WHO-hosted committee ensuring technical assistance to countries during yearly country visits and on an ad hoc basis via email or telephone, ensures that MDR-TB patients are prescribed 


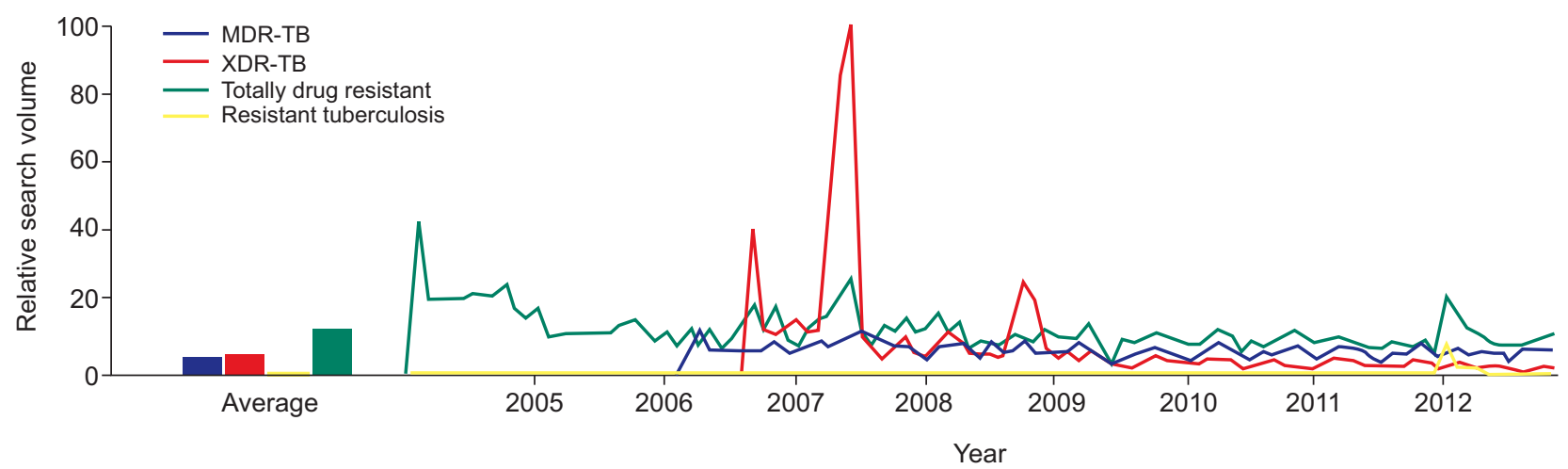

FIGURE 1. Web search interest for "MDR-TB", "XDR-TB", "totally drug resistant" and "resistant tuberculosis" worldwide from 2004 to present (source: Google Trends) On the $y$-axis the number 100 represents the peak search volume.

treatment in line with the WHO guidelines, the latest scientific evidence and country experiences. Through its technical assistance, several high MDR-TB burden countries in the WHO European Region have introduced these mechanisms at the national level. However, to date, no online mechanism exists to facilitate peer-to-peer consultation at supranational level.

The majority of low TB incidence countries, which do not need to apply for donor funding, do not have a similar consultation body, even though expertise to manage MDR- or XDR-TB cases in these settings is often limited. The challenge of providing proper treatment to MDR- or XDR-TB patients has been identified in several countries in the region. In these countries, consilia or similar structures have been established to reach a consensus on the best treatment approach for MDR- or XDRTB patients. However, most of these consilia have limited experience or cover only a fraction of the patients in the country.

\section{TABLE 1 \\ Estimated proportion of multidrug-resistant tuberculosis (MDR-TB) cases among TB notified cases and absolute} number of MDR-TB cases notified, 2011

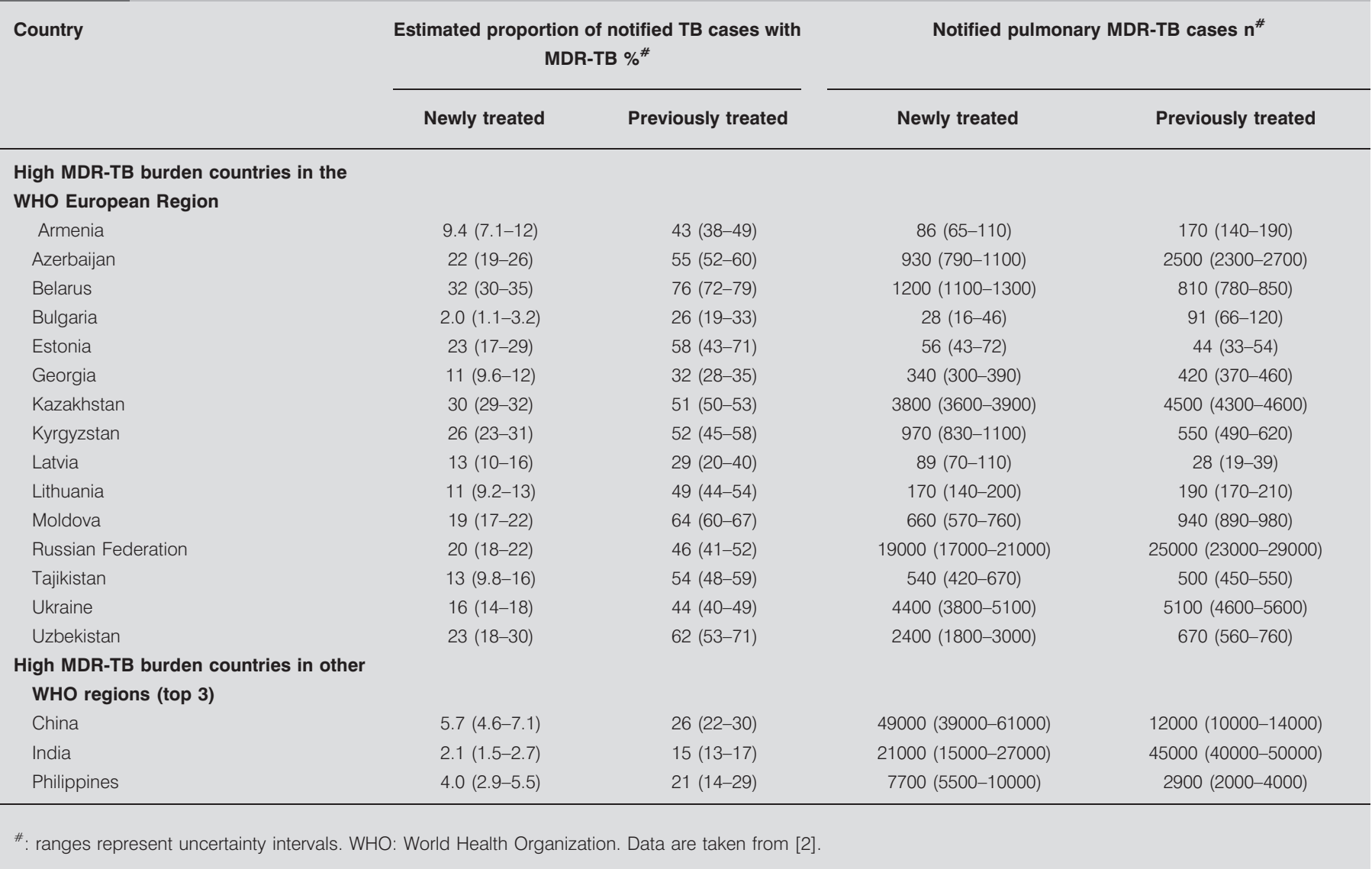


In European countries without a formal system of consultation, specialised staff from reference centres spend a significant proportion of their working time responding to phone or e-mail clinical queries from all over the country on an ad hoc basis and without any formal recognition, monitoring or support for the service offered.

A recent European Respiratory Society (ERS)/European Centre for Disease Prevention and Control (ECDC) study [14] has demonstrated several clinical and public health MDR-TB management shortcomings in some of the low TB incidence countries of the European Union (EU). The existence of WHO guidelines and European Standards of TB care is apparently insufficient to guarantee appropriate treatment of MDR- and XDR-TB. Rapid advice from a multidisciplinary team with clinical and management experience at national or supranational level will help ensure proper treatment $[15,16]$.

The WHO Regional Office for Europe, ECDC, the Union, documents originating from the Wolfheze workshops (periodic expert meetings setting the scene for improved TB control and elimination in Europe) and national TB control programme managers' meetings [17] have recognised the significance of national and supranational consultation from clinical and public health perspectives.

\begin{tabular}{|c|c|c|c|}
\hline \multirow{2}{*}{$\begin{array}{l}\text { TABLE } 2 \\
\text { Country }\end{array}$} & \multicolumn{3}{|c|}{$\begin{array}{l}\text { Treatment outcomes (success and death) of the } \\
\text { multidrug-resistant tuberculosis (MDR-TB) case } \\
\text { cohort enrolled in } 2007 \text { in the high burden } \\
\text { countries of the World Health Organization (WHO) } \\
\text { European Region }\end{array}$} \\
\hline & & $\begin{array}{l}\text { Treatment } \\
\text { success \% }\end{array}$ & Deaths \% \\
\hline \multicolumn{4}{|c|}{$\begin{array}{l}\text { High MDR-TB burden countries } \\
\text { in the WHO European Region }\end{array}$} \\
\hline Armenia & & 53 & 11 \\
\hline Azerbaijan & & $56.5^{\#}$ & $8.7^{\#}$ \\
\hline Belarus & & NA & NA \\
\hline Bulgaria & & 25 & 45 \\
\hline Estonia & & 57 & 14 \\
\hline Georgia & & 38 & 20 \\
\hline Kazakhstan & & 77 & 4 \\
\hline Kyrgyzstan & & 50 & 5 \\
\hline Latvia & & 64 & 15 \\
\hline Lithuania & & NA & NA \\
\hline Moldova & & 52 & 8 \\
\hline Russian Fe & eration & $50.9^{\#}$ & $8.1^{\#}$ \\
\hline Tajikistan & & NA & NA \\
\hline Ukraine & & NA & NA \\
\hline Uzbekistan & & 55 & 10 \\
\hline \multicolumn{4}{|c|}{$\begin{array}{l}\text { High MDR-TB burden countries } \\
\text { in other WHO Regions (top 3) }\end{array}$} \\
\hline China & & NA & NA \\
\hline India & & NA & NA \\
\hline Philippines & & 63 & 11 \\
\hline
\end{tabular}

Data from [9], except \#: country data from [10], 2008 cohort. NA: not available.
The ERS has increased its commitment towards TB control and elimination in Europe through different initiatives, including the European Respiratory Roadmap [18] initiative aimed at providing evidence on the need to support lung health. In 2012, at the ERS summit in Tallinn, the role and contribution of health inequalities in sustaining TB were discussed. In addition the European Forum for TB innovation has become part of the 2013 Presidential plan, and is focused on innovative interventions that can already be implemented based on the evidence that is presently available [19].

To extend this and after consultation with WHO/Europe and ECDC, and under the ERS Presidential initiative, the ERSWHO Electronic Consilium was launched during the 22nd ERS Congress in Vienna, on September 6, 2012. The WHO Regional Office for Europe signed a Memorandum of Understanding with the ERS to coordinate and co-manage this initiative, which also has the support of ECDC in public health and monitoring and evaluation aspects.

The overarching aim of this initiative is to provide scientifically sound and evidence-based advice to national consilia and individual clinicians. Its primary objective is to provide clinical consultation for drug-resistant TB and other difficult-to-treat TB cases, including co-infection with HIV and paediatric cases. Through clinical action, the main contribution and outcome of the initiative will be a public health response aimed at preventing further development of drug resistance. Its secondary objective is to ensure monitoring and evaluation of clinical practices (diagnosis, treatment and prevention) in the WHO European Region; this will allow comparisons with established standards for designing interventions to address the common pitfalls. In addition the system will allow transborder follow-up of difficult-to-treat cases moving from one country to another within Europe.

The ERS/WHO Consilium will provide a free-to-access, bilingual (English and Russian) internet-based consultation system able to provide suggestions on clinical management of complicated TB cases with a turnaround time of about 1 week. The launch of the initiative has been followed with a call for experts (including TB clinicians, but also other professionals relevant for patient management). The expert applications have then been reviewed and validated by a ERS/WHO/ ECDC review team based on strict criteria.

As well as supporting clinicians in Europe (and eventually, in a second phase, outside of Europe), the system will also enable evaluation of the trends in key challenges and pitfalls which can be addressed through human resources capacity building, including MDR- and XDR-TB management practices (e.g. diagnostic and prescription habits), and clinicians' compliance with WHO and other international, evidence-based guidelines. The system will also enable evaluation of trends over time.

The Electronic Consilium is particularly relevant for the ERS and ECDC, as evaluation of how the recently published EU Standards for TB Care $[16,20]$ are applied is considered a priority.

We are particularly grateful to the European Respiratory Journal (a journal particularly committed to TB) for hosting this editorial and allowing a wider audience to become aware of this important initiative. 
As this initiative requires a large consensus and significant support, all clinicians of goodwill are welcome to adhere and contribute, to the extent they can, to help their colleagues who need urgent suggestions to solve burning clinical dilemmas emerging from day-to-day practice.

The platform for the Electronic Consilium can be found on the ERS website and soon the links will be provided on the WHO/ Europe and ECDC websites.

\section{STATEMENT OF INTEREST}

None declared.

\section{REFERENCES}

1 Raviglione M, Marais B, Floyd K, et al. Scaling up interventions to achieve global tuberculosis control: progress and new developments. Lancet 2012; 379: 1902-1913.

2 World Health Organization. Global Tuberculosis Report. Geneva, WHO Press, 2012. Available from: http://apps.who.int/iris/ bitstream/10665/75938/1/9789241564502_eng.pdf

3 Zignol M, van Gemert W, Falzon D, et al. Surveillance of antituberculosis drug resistance in the world: an updated analysis, 2007-2010. Bull World Health Organ 2012; 90: 111-119D.

4 Matteelli A, Centis R, D'Ambrosio L, et al. Multidrug-resistant tuberculosis today. Bull World Health Organ 2012; 90: 78.

5 Abubakar I, Dara M, Manissero D, et al. Tackling the spread of drug-resistant tuberculosis in Europe. Lancet 2012; 379: e21-e23.

6 Dara M, Kluge H. Roadmap to Prevent and Combat DrugResistant Tuberculosis. Copenhagen, WHO Regional Office for Europe, 2011. Available from: http://www.euro.who.int/_data/ assets/pdf_file/0014/152015/e95786.pdf

7 Skrahina A, Hurevich H, Zalutskaya A, et al. Alarming levels of drug-resistant tuberculosis in Belarus: results of a survey in Minsk. Eur Respir J 2012; 39: 1425-1431.

8 Migliori GB, Dara M, de Colombani P, et al. Multidrug-resistant tuberculosis in Eastern Europe: still on the increase? Eur Respir J 2012; 39: 1290-1291.

9 World Health Organization. Towards Universal Access to Diagnosis and Treatment of Multidrug-Resistant and Extensively
Drug-Resistant Tuberculosis by 2015: WHO Progress Report 2011. Geneva, WHO press, 2011. Available from: www.who.int/tb/ publications/2011/mdr_report_2011/en/index.html

10 European Centre for Disease Prevention and Control/WHO Regional Office for Europe. Tuberculosis Surveillance and Monitoring in Europe 2012. Stockholm, European Centre for Disease Prevention and Control, 2012. Available from: www.euro. who.int/__data/assets/pdf_file/0006/168468/2012-Annual-TBSurveillance-Report.pdf

11 Ahuja SD, Ashkin D, Avendano M, et al. Multidrug resistant pulmonary tuberculosis treatment regimens and patient outcomes: an individual patient data meta-analysis of 9,153 patients. PLoS Med 2012; 9: e1001300.

12 Falzon D, Gandhi N, Migliori GB, et al. Resistance to fluoroquinolones and second-line injectable drugs: impact on MDR-TB outcomes. Eur Respir J 2012 [in press: DOI: 10.1183/09031936. 00134712].

13 Migliori GB, Sotgiu G, Gandhi NR, et al. Drug resistance beyond XDR-TB: results from a large individual patient data metaanalysis. Eur Respir J 2012 [in press: DOI: 10.1183/09031936. 00136312].

14 Migliori GB, Sotgiu G, D'Ambrosio L, et al. TB and MDR/XDR-TB in European Union and European Economic Area countries: managed or mismanaged? Eur Respir J 2012; 39: 619-625.

15 Falzon D, Jaramillo E, Schünemann HJ, et al. WHO guidelines for the programmatic management of drug-resistant tuberculosis: 2011 update. Eur Respir J 2011; 38: 516-528.

16 Migliori GB, Zellweger JP, Abubakar I, et al. European union standards for tuberculosis care. Eur Respir J 2012; 39: 807-819.

17 Veen J, Migliori GB, Raviglione MC, et al. Harmonisation of TB control in the WHO European region: the history of the Wolfheze Workshops. Eur Respir J 2011; 37: 950-959.

18 Decramer M, Sibille Y, eds. European Respiratory Roadmap. Lausanne, European Respiratory Society, 2011.

19 Blasi F, Reichman LB, Migliori GB. Presenting the European Forum for TB Innovation: innovative thinking in progressing towards TB elimination in Europe. Eur Respir J 2012; 40: 806-8.

20 Migliori GB, Sotgiu G, Blasi F, et al. Towards the development of EU/EEA Standards for Tuberculosis Care (ESTC). Eur Respir J 2011; 38: 493-495. 